\title{
Glycogen Storage Disease Type I
}

National Cancer Institute

\section{Source}

National Cancer Institute. Glycogen Storage Disease Type I. NCI Thesaurus. Code

C84733.

An autosomal recessive inherited type of glycogen storage disease. It is characterized by a deficiency of the enzyme glucose-6-phosphatase, resulting in the inability of the liver to produce free glucose causing severe hypoglycemia. There is abnormal accumulation of glycogen in the liver and kidneys. 